\title{
API/FDF Analytical Testing Site
}

National Cancer Institute

\section{Source}

National Cancer Institute. API/FDF Analytical Testing Site. NCI Thesaurus. Code C101509.

Sites that perform testing of the characteristics and attributes of active pharmaceutical ing redients or finished dosage forms. 